\title{
ReSEARChArticle
}

\section{Field evaluation of Trichoderma Viride for wilt management in chickpea crop}

\author{
AJIT SINGH VATS, A.K. SINGH AND M.K. PANDEY
}

\section{SUMMARY}

Chickpea is one of the important pulse crops of the Faizabad district among pulses which is affected by the Fusarium wilt (Fusarium udum) disease causing severe yield loss. An eco-friendly integrated disease management technology, particularly use of Trichoderma as seed and soil treatment with rotted FYM have been evaluated on large area of farmers' field during Rabi 2012-13 and 2013-14 in the Madhupur, Anjana and Magalsi villages of Faizabad district (Uttar Pradesh) through on farm trial. Grain yield of chick pea and incidence of wilt were significantly less under Trichoderma treatment and was much superior over the control. Soil and seed treatments with Trichoderma resulted in lowering the wilt disease and considerably increased grain yield of chick pea over farmers' practice. The use of Trichoderma for the management of wilt was very much appreciated by the farmers. The success of Trichoderma in the target villages outlines the need for its popularization in larger areas.

Key Words : On farm trial, Chickpea, Trichoderma

How to cite this article : Vats, Ajit Singh, Singh, A.K. and Pandey, M.K. (2016). Field evaluation of Trichoderma Viride for wilt management in chickpea crop. Internat. J. Plant Sci., 11 (2): 233-236, DOI: 10.15740/HAS/IJPS/11.2/233-236.

Article chronicle : Received : 01.02.2016; Revised : 16.04.2016; Accepted : 30.05.2016 